Thorax (1973), 28, 183.

\title{
Bacteraemia after open-heart surgery
}

\author{
EUNICE LOCKEY, LORENZO GONZALEZ-LAVIN, \\ IR A RAY, and RUTH CHEN \\ National Heart Hospital and Institute of Cardiology, London
}

\begin{abstract}
We have analysed the bacteraemias occurring before discharge from hospital in patients subjected to open-heart surgery. The overall incidence was $2.7 \%$. The predominant organisms at first were staphylococci and streptococci, but in the later years of the study almost all positive blood cultures were due to Gram-negative bacilli. Short-term prophylactic antibiotics were used throughout. Eleven of the 12 Gram-positive bacteraemias occurred after the period of antibiotic prophylaxis ; eight of the patients had endocarditis and a further three had serious wound infections. Most of the 32 Gram-negative bacillaemias occurred while antibiotics were being given. Some were transient phenomena in well patients; others were associated with terminal states. Infection was a major cause of death in four patients, however, and two patients had endocarditis. Serratia, providence, hafnia, and citrobacter were all identified as well as the more usual escherichia, klebsiella, and pseudomonas. We discuss the possible origins and management of these bacteraemias.
\end{abstract}

\section{PATIENTS AND METHODS}

We report a study of the bacteraemias which occurred in 1,640 consecutive patients after open-heart surgery at the National Heart Hospital, London between January 1964 and December 1970.

Fever for several days and raised blood sedimentation rate are common events after heart surgery, and the reason for taking a blood culture was more often the fear of endocarditis as a complication than any specific sign or symptom of this disease. Any patient who appeared less well than expected and those in whom septicaemia or endocarditis was clinically probable had blood cultures taken.

Standard methods of isolation were used and identification was according to the methods of Cowan and Steel (1965).

All patients received prophylactic antibiotics. The regimen most commonly used was a combination of cloxacillin (500 mg 6-hourly) and streptomycin (1 g daily) given first at the time of premedication and continued for five days after operation. Gentamicin was used instead of streptomycin from April 1970. It was given twice daily in a dose based on $4 \mathrm{mg} / \mathrm{kg}$ per day for the first two days and then on $2 \mathrm{mg} / \mathrm{kg}$ per day for the next three. Gentamicin and streptomycin were both used with caution if renal function was impaired.

\section{RESULTS}

Forty-four patients had positive blood cultures in the postoperative period, an overall incidence of $2.7 \%$. The incidence in any given year ranged from nil to $5 \cdot 8 \%$ (Table I). Endocarditis was thought to be present in 10 patients, two having more than one attack, and in six this was proven at either necropsy or re-operation. Endocarditis was proven absent in 17 patients, while in a further 17 it was almost certainly absent judging from the clinical course. Table II shows that endo-

T A B L E I POSTOPERATIVE BACTERAEMIAS

\begin{tabular}{|c|c|c|c|c|c|c|c|}
\hline & 1964 & 1965 & 1966 & 1957 & 1968 & 1969 & 1970 \\
\hline $\begin{array}{l}\text { No. of } \\
\text { operations } \\
\text { No. of } \\
\text { patients } \\
\text { with } \\
\text { positive } \\
\text { blood } \\
\text { cultures }\end{array}$ & $\begin{array}{c}85 \\
4 \\
(4 \cdot 7 \%)\end{array}$ & $\begin{array}{c}107 \\
\text { None }\end{array}$ & $\begin{array}{c}159 \\
1 \\
(0.6 \%)\end{array}$ & $\begin{array}{c}250 \\
7 \\
(2 \cdot 8 \%)\end{array}$ & $\begin{array}{c}320 \\
3 \\
(0.9 \%)\end{array}$ & $\begin{array}{c}359 \\
21 \\
(5 \cdot 8 \%\end{array}$ & $\begin{array}{c}360 \\
8 \\
(2 \cdot 2 \%)\end{array}$ \\
\hline $\begin{array}{c}\text { Organism } \\
\text { Gram- } \\
\text { positive } \\
\text { Gram- } \\
\text { negative } \\
\text { Fungus }\end{array}$ & $\begin{array}{c}4 \\
\text { None } \\
1\end{array}$ & $\begin{array}{l}\text { None } \\
\text { None } \\
\text { None }\end{array}$ & $\begin{array}{c}1 \\
\text { None } \\
1\end{array}$ & $\begin{array}{l}3 \\
4 \\
1\end{array}$ & $\begin{array}{c}2 \\
2 \\
\text { None }\end{array}$ & $\begin{array}{c}1 \\
20 \\
\text { None }\end{array}$ & $\begin{array}{c}1 \\
7 \\
\text { None }\end{array}$ \\
\hline
\end{tabular}

T A B L E I I

ENDOCARDITIS AND INFECTING ORGANISM

\begin{tabular}{|c|c|c|c|c|}
\hline \multirow{2}{*}{$\begin{array}{c}\text { Type of } \\
\text { Organism }\end{array}$} & \multicolumn{2}{|c|}{$\begin{array}{c}\text { Endocarditis } \\
\text { Present }\end{array}$} & \multicolumn{2}{|c|}{$\begin{array}{c}\text { Endocarditis } \\
\text { Absent }\end{array}$} \\
\hline & Proven & Probable & Proven & Probable \\
\hline $\begin{array}{l}\text { Gram-positive } \\
\text { (11 of } 12=\text { cocci) } \\
\text { Gram-negative } \\
\text { bacilli } \\
\text { Fungus }\end{array}$ & $\begin{array}{l}4 \\
2 \\
1\end{array}$ & $\begin{array}{l}4 \\
0 \\
1\end{array}$ & $\begin{array}{l}2 \\
15 \\
1\end{array}$ & $\begin{array}{c}2 \\
15 \\
0\end{array}$ \\
\hline
\end{tabular}


carditis was rare in the patients with Gram-negative bacillaemia but common with the Grampositive organisms.

INFECTIONS DUE TO GRAM-POSITIVE ORGANISMS Gram-positive organisms were isolated from 12 patients. These organisms accounted for all the positive blood cultures due to bacteria before 1967, and for half of those occurring in 1967 and 1968 , but for only two out of 29 in 1969 and 1970. In 11 of the 12 patients the infection occurred after the period of antibiotic cover had been completed (10 to 32 days after operation).

Nine of the organisms were staphylococci (five coagulase-positive, four coagulase-negative), two were $\beta$-haemolytic streptococci, and one was Listeria monocytogenes.

Wound infections were the probable source of the organism in most patients. Eight patients were treated for endocarditis, five successfully. In only one patient was the bacteraemia considered to be of no consequence clinically.

Five patients died. There was no evidence of endocarditis in two (one prosthesis, one homograft), although it had been suspected in life and the prosthetic valve was found to be partially detached. The other died of haemorrhage from his infected aorta, staphylococci and Candida being isolated both from the wound and from blood cultures. Endocarditis was present in three patients (two prosthetic, one homograft) and in all, the original organism was isolated from the valve vegetations at necropsy. Treatment had been intensive in the two patients with prosthetic valves and blood cultures had become negative for the original organism during life. Candida was isolated from the bloodstream of one patient two days before death and this organism was also present in the vegetations. In the other patient, endocarditis had not been suspected and he died from an overwhelming septicaemia shortly after resuture of an infected sternum.

Five patients had second bacteraemic episodes. In one, pseudomonas was isolated from three sets of blood cultures after five weeks' intravenous penicillin therapy. He was then clinically well. All treatment was stopped and he remained well. In another, $\beta$-haemolytic streptococci were isolated after the mitral and aortic valves had been replaced for proven Coxiella burneti infection. She had received prolonged treatment with tetracycline to which the streptococci were resistant. She was first given a 10-day course of penicillin but the bacteraemia recurred and she was then given the standard six-week course. The origin of the streptococci was never found. Candida was isolated from the bloodstream of the other three patients, all of whom were under treatment for staphylococcal infections. Two who died have already been discussed. The other had a second attack of staphylococcal septicaemia after five weeks' antifungal therapy with amphotericin B. Cloxacillin was also given and he survived.

GRAM-NEGATIVE BACILlaEMIAS Gram-negative bacilli were isolated from the bloodstreams of 32 patients. None was isolated in the first three of the seven years studied. Half of the positive blood cultures in 1967 and 1968 were due to them. In the last two years, 27 of the 29 organisms isolated were Gram-negative bacilli. Seventy per cent of the bacillaemias occurred within the period of antibiotic cover. No organism was sensitive to cloxacillin and only three out of 25 tested were sensitive to streptomycin. All those tested were sensitive to gentamicin.

Two organisms, pseudomonas and klebsiella, were isolated at the same time from one patient. Pseudomonas was isolated from three patients in all. The other 30 organisms were members of the entero-bacteraciae. Eighteen were identified as belonging to the following genera: klebsiella, escherichia, serratia, providence, citrobacter, and hafnia. Twelve were not fully characterized.

Foci of infection were apparent in 13 patients. Thus the organism cultured from the bloodstream was first isolated from the wounds of six patients and from an empyema in a seventh. Two further patients were later shown to have deeper seated focal sepsis (infected false aneurysm, infected aortotomy site). In three patients, the organism was present in the urinary tract before it appeared in the bloodstream, and in the thirteenth it had been isolated from the ear before operation. In two patients the organism was isolated first from the sputum, but the evidence suggested colonization of the respiratory tract rather than lung infection.

In the other 19 patients there was no obvious nidus of infection. In 10 of them the bacillaemia was a transient phenomenon in an otherwise smooth postoperative course. Blood cultures were taken because of a single rigor, a short period of unexpected vasoconstriction, or a rather higher temperature than usual. Nine of the patients were within five days of surgery and seven had intravenous catheters in situ at the time. The fluid in the drip bottle and line was sterile in all, however, except where contaminated with the patient's blood.

The other nine patients in whom no source 
for the bacillaemia could be found had very complicated postoperative courses. Thus five were given steroids because of brain damage, five were dialysed because of renal failure, six needed continual ventilatory support, one was a severe diabetic, and three had acute gastrointestinal episodes-pancreatitis, bleeding gastric ulcer, and multiple bowel infarcts. Most of them required vasopressor support for many days after surgery and all died.

Positive blood cultures were obtained from two patients with sternal wound infections after resuture of the sternum. One died in a state of septicaemic shock. In another, the positive cultures coincided with a period of mesenteric embolization. Bacillaemia recurred in two patients after antibiotic therapy was discontinued. In one, deepseated sepsis was found and in the other the focus was probably the ear. Renal failure was due to bacillaemia in two patients.

Sixteen patients died, and infection was a major factor in four. Relatively uncommon bacilli, providence and serratia, were responsible in two patients. Endocarditis was proven present in two patients only. In one, an infected false aneurysm formed around an aortic homograft in the pulmonary position. This ruptured but was successfully excised and replaced. The other patient died from rupture of an infected aortic cannulation site. At necropsy microscopic evidence of endocarditis was obtained. Endocarditis was proven absent in 15 patients and was clinically unlikely in the other 15 .

\section{DISCUSSION}

Our overall incidence of positive blood cultures after open-heart surgery in the seven-year period 1964-70 was $2 \cdot 7 \%$, but less than one-quarter of these had endocarditis. The highest incidence of bacteraemia was found in late 1969 and early 1970 when many more patients had blood cultures taken, confirming the finding of Crowley (1970) that the incidence of positive blood cultures is related not to the total number of blood cultures taken but to the total number of patients investigated in this way.

The predominant organism changed from Gram-positive cocci to Gram-negative bacilli during the period studied. An increasing incidence of Gram-negative infection in hospital practice is now a well-recognized phenomenon and antibiotics undoubtedly contribute to this. The increased incidence of Gram-negative bacillaemias since the introduction of antibacterial agents is reported by Denton et al. (1957) and Finland,
Jones, and Barnes (1959) while others have recorded rapid Gram-negative colonization of various sites (Redman and Lockey, 1967 ; Mummery, Bradley, and Jeffries, 1971; Devetski, Tillman, Norsen, and Lepper, 1963 ; Montgomerie, Doak, Taylor, and North, 1970). The resistance of the patient influences the type of organism. Johanson, Pierce, and Sanford (1969) report that Gramnegative colonization of the pharynx is common in the sick but rare in the healthy hospital patient even when no antibiotics are used, while Gramnegative bacillaemia is extensively reported in immunosuppressed patients whether the immunosuppression is due to steroids, uraemia or cytotoxic drugs (Brumfitt and Leigh, 1969; Grant, Horowitz, and Lorian, 1969 ; Abrams, Zierdt, and Brown, 1971 ; Mummery et al., 1971).

The origin of the bacteraemia could reasonably be postulated as from the wound or urine in many of our patients. In others, no obvious focus could be found either in the patient or in his surroundings and attendants. Montgomerie et al. (1970) have recently shown that kTebsiella isolated from wounds were of identical serotype to organisms isolated earlier from the faeces of their patients; Bettelheim, Dulake, and Taylor (1971) have shown that escherichia responsible for postoperative urinary tract infections were identical in serotype and biochemical properties to those present in the patient's own rectum or vagina or both before operation. While bacillaemia in patients whose normal defence mechanisms against infection are impaired is not surprising, the incidence of positive blood cultures in apparently well patients is unexpected. We suspect that fleeting bacillaemia may be much commoner after operation than is supposed.

Gram-negative bacilli belonging to relatively uncommon genera constituted an unexpectedly high proportion of those fully identified in our series. Black and Hodgson (1971) have commented on the apparent rareness of serratia as a pathogen in Britain and its frequency in America where septicaemia and endocarditis are described (Altemeier, Culbertson, Fullen, and McDonough, 1969 ; Quintiliani and Gifford, 1969). Bacteraemia due to providence and citrobacter is also documented (Janis, Evans, and Hoeprich, 1968; Grant et al., 1969). Three of the 16 patients in our series who died had infections with uncommon bacilli-two with providence and one with serratia - and the death of one was directly attributable to infection.

Endocarditis was never postulated as the origin, nor expected as a consequence of those Gramnegative bacillaemias which were fleeting or 
terminal. Blood cultures were taken from most patients with Gram-positive infections because endocarditis was clinically suspected. It is not surprising, therefore, that in our series the incidence of proven or highly probable endocarditis was $67 \%$ in the patients with Gram-positive bacteraemias but only $6 \%$ in those with Gram. negative bacillaemias.

Staphylococci are ubiquitous and commonly isolated from floors and surfaces whatever the cleaning method. They are also present in the nasopharynx and on the hands of most attendants and found in profusion near scrub sinks which in our hospital are sited inside the operating rooms. Five of our 12 patients with Grampositive bacteraemia died, and in four of those who died the organism was a staphylococcus (both coagulase-positive and coagulase-negative). Clarkson and Barratt-Boyes (1970) reported the deaths of four of their five patients who developed postoperative staphylococcal endocarditis. We therefore feel that a prophylactic antibiotic against this organism is essential and should be given immediately before surgery and for a short period afterwards. Most recent reports agree with this approach (Shafer and Hall, 1970; Gonzalez-Lavin, Blanco, and Nichols, 1970 ; Fekety et al., 1969 ; Firor, 1967 ; Goodman et al., 1968 ; Yeh et al., 1967). We prefer flucloxacillin.

Gram-negative bacilli, although present in profusion in the intestinal tract, are only rarely isolated from the nasopharynx or hands of the attendants or the environment. Most effective antibiotics have toxic side effects and cannot be used in adequate dosage until good renal function is assured. Seventy per cent of Gram-negative bacillaemias in this series occurred within the period of antibiotic prophylaxis; streptomycin was used for most of the period under review and we did not recognize that a high percentage of organisms were resistant to it and to cephaloridine, kanamycin, carbenicillin, and ampicillin. Many of the Gram-negative bacillaemias are transient or terminal and we are not convinced of the value of a prophylactic regime against Gram-negative organisms. If one is used, we consider gentamicin the most effective. All organisms tested have proved sensitive to gentamicin. No resistant strains have emerged over the past two years.

Postoperatively the indications for antibiotic therapy are not always easy to define. Endocarditis can be very difficult to diagnose clinically. while a pure heavy growth of an organism from a tracheostomy site or sputum may indicate colonization only. When the signs of endocarditis are absent, the length of the antibiotic course is difficult to prescribe. We have seen fungal superinfection in three patients subjected to prolonged intravenous antibiotic therapy, but have also seen recrudescence of the original organism in three patients in whom shorter antibiotic courses were used (10 to 14 days). We now regard the appearance of Candida at other sites (urinary tract, intravenous catheter site, wounds, sputum) as a possible preliminary to its appearance in the bloodstream in debilitated patients, particularly those receiving steroids and intravenous antibiotics (Conway, Kothari, Lockey, and Yacoub, 1968). If a short course of antibiotics is regarded as appropriate in a patient with a positive blood culture, repeated blood cultures at the end of the course of treatment are necessary.

It is important to perform any subsequent operation, particularly involving the original incision, under antibiotic cover whether or not infection is apparent. Two of our patients in whom this was not done died of septicaemic shock.

We would stress that sterilization of the blood does not necessarily indicate successful antibiotic therapy. The original organism was isolated from the prosthetic valve at re-operation in two of our patients although it had disappeared from the bloodstream. Earlier surgery might have been life-saving.

\section{REFERENCES}

Abrams, E., Zierdt, C. H., and Brown, J. A. (1971). Observations on Aeromonas hydrophila septicaemia in a patient with leukaemia. J. clin. Path., 24, 491.

Altemeier, W. A., Culbertson, W. R., Fullen, W. D., and McDonough, J. J. (1969). Serratia marcescens septicaemia: A new threat to surgery. Arch. Surg., 99, 232.

Bettelheim, K. A., Dulake, C., and Taylor, J. (1971). Postoperative urinary infections caused by Escherichia coli. J. clin. Path., 24, 442.

Black, W. A., and Hodgson, R. (1971). Search for serratia. J. clin. Path., 24, 444.

Brumfitt, W., and Leigh, D. A. (1969). The incidence and bacteriology of bacteraemia-a study at two hospitals. Proc. roy. Soc. Med., 62, 1239.

Clarkson, P. M., and Barratt-Boyes, B. G. (1970). Bacterial endocarditis following homograft replacement of the aortic valve. Circulation, 42, 987.

Conway, N., Kothari, M. L., Lockey, E., and Yacoub, M. H. (1968). Candida endocarditis after heart surgery. Thorax, 23, 353.

Cowan, S. T., and Steel, K. J. (1965). Manual for the Identification of Medical Bacteria. Cambridge University Press. 
Crowley, N. (1970). Some bacteraemias encountered in hospital practice. J. clin. Path., 23, 166.

Denton, C., Pappas, E. G., Uricchio, J. F., Goldberg, H., and Likoff, W. (1957). Bacterial endocarditis following cardiac surgery. Circulation, 15, 525.

Devetski, R., Tillman, P., Norsen, J., and Lepper, M. (1963). Emergence of antibiotic-resistant Escherichia coli in a closed population when chloramphenicol was used extensively. Antimicrob. Agents Chemother,. 3, 714.

Fekety, F. R., Cluff, L. E., Sabiston, D. C. Jr., Seidl, L. G., Smith, J. W., and Thoburn, R. (1969). A study of antibiotic prophylaxis in cardiac surgery. $J$. thorac. cardiovasc. Surg., 57, 757.

Finland, M., Jones, W. F., and Barnes, M. W. (1959). Occurrence of serious bacterial infections since introduction of antibacterial agents. J. Amer. med. Ass., 170, 2188.

Firor, W. B. (1967). Infection following open-heart surgery, with special reference to the role of prophylactic antibiotics. J. thorac. cardiovasc. Surg., 53, 371.

Gonzalez-Lavin, L., Blanco, G., and Nichols, H. T. (1970). Sodium cephalothin in open-heart surgery. Clin. Med., No. 12, 77, 31.

Goodman, J. S., Schaffner, W., Collins, H. A., Battersby, E. J., and Koenig, M. G. (1968). Infection after cardiovascular surgery. Clinical study including examination of antimicrobial prophylaxis. New Engl. J. Med., 278, 117.
Grant, M. D., Horowitz, H. I., and Lorian, V. (1969). Gangrenous ulcer and septicaemia due to citrobacter. New Engl. J. Med., 280, 1286.

Janis, B., Evans, R. G., and Hoeprich, P. D. (1968). Providence bacillus bacteremia and septicopyaemia. Amer. J. Med., 45, 943.

Johanson, W. G., Pierce, A. K., and Sanford, J. P. (1969). Changing pharyngeal bacterial flora of hospitalized patients. New Engl. J. Med., 281, 1137.

Montgomerie, J. Z., Doak, P. B., Taylor, D. E. M., and North, J. D. K. (1970). Klebsiella in faecal flora of renal-transplant patients. Lancet, 2, 787.

Mummery, R. V., Bradley, J. M., and Jeffries, D. J. (1971). Microbiological monitoring of patients in hepatic failure with particular reference to extra-corporeal porcine liver perfusion. Lancet, 2, 60 .

Quintiliani, R., and Gifford, R. H. (1969). Endocarditis from Serratia marcescens. J. Amer. med. Ass., 208, 2055.

Redman, L. R., and Lockey, E. (1967). Colonisation of the upper respiratory tract with gram-negative bacilli after operation, endotracheal intubation and prophylactic antibiotic therapy. Anaesthesia, 22, 220.

Shafer, R. B., and Hall, W. H. (1970). Bacterial endocarditis following open heart surgery. Amer. J. Cardiol. 25, 602.

Yeh, T. J., Anabtawi, I. N., Cornett, V. E., White, A., Stern, W. H., and Ellison, R. G. (1967). Bacterial endocarditis following open-heart surgery. Ann. thorac. Surg., 3, 29. 